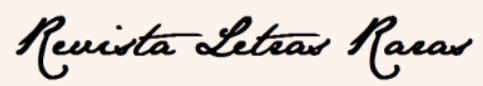

ISSN: 2317-2347 - v. 7, Edição Especial (2018).

\title{
A aventura heroica na narrativa $O$ Hobbit de J. R. R. Tolkien /
}

\author{
The heroic adventure in the narrative The Hobbit by J. R. R. Tolkien
}

\author{
Ismael Arruda Nazario da Silva - UERN* \\ Livia Maria Rosa Soares - UERN**
}

\begin{abstract}
RESUMO
Bilbo Bolseiro, protagonista da narrativa $O$ Hobbit, de J. R. R. Tolkien, ingressa em uma aventura heroica pela Terra-média na companhia de doze anões e um mago. A jornada realizada por ele o permite passar por um processo de desenvolvimento interior. A narrativa o conduz a lugares perigosos e maravilhosos, que colocam sua coragem e outros atributos em prova. Em vista disso, objetivamos investigar a jornada heroica empreendida pelo protagonista Bilbo, no conto de fadas citado, e verificar como ela acarreta mudanças para o hobbit. Para tanto, utilizaremos os estudos de Campbell (2007a), acerca do monomito e da jornada heroica, como aporte teórico-metodológico principal deste trabalho, e o estudo de Tolkien (2013) acerca do conto de fadas. Nos valeremos também do Dicionário de Símbolos de Chevalier e Gheerbrant (2009) no entendimento dos símbolos que aparecem na narrativa. Analisaremos a história segundo as fases de desenvolvimento propostas por Campbell: Partida, Iniciação e Retorno. Após mapearmos a aventura, comprovamos que o hobbit muda consideravelmente sua forma de perceber o mundo que o cerca e a si próprio no final da narrativa, apresentando um conjunto de características que ele não apresentava antes da aventura.
\end{abstract}

PALAVRAS-CHAVE: Literatura; O Hobbit; Jornada do herói.

\section{ABSTRACT}

Bilbo Bolseiro, protagonist of the narrative The Hobbit, by J. R. R. Tolkien, enters a heroic adventure through Middle-earth in the company of twelve dwarves and a wizard. The journey undertaken by him allows him to undergo a process of interior development. The narrative leads him to dangerous and wonderful places that put his courage and other attributes to the test. In view of this, we aim to investigate the heroic journey undertaken by the protagonist, Bilbo, in the fairy tale quoted, and to verify how it entails changes for the hobbit. For that, we will use Campbell's (2007a) studies on the monomyth and the heroic journey as the main theoretical-methodological contribution of this work, and Tolkien's (2013) study of the fairy tale. We will also use the Symbols Dictionary of Chevalier and Gheerbrant (2009) in the understanding of the symbols that appear in the narrative. We will analyze the store according to the stages of development proposed by Campbell: departure, initiation and return. After mapping the adventure, we found that the hobbit changes considerably his way of perceiving the world that surrounds him and himself at the end of the narrative, presenting a set of characteristics that he did not present before the adventure.

KEYWORDS: Literature; The Hobbit; Hero's journey.

\section{Introdução}

\footnotetext{
* Mestrando da linha de pesquisa Texto Literário, Crítica e Cultura, do Programa de Pós-graduação em Letras (PPGL), da Universidade do Estado do Rio Grande do Norte - UERN, Pau dos Ferros, Rio Grande do Norte, Brasil, will_dublin@outlook.com

** Doutoranda da linha de pesquisa Texto Literário, Crítica e Cultura, do Programa de Pós-graduação em Letras (PPGL) da Universidade do Estado do Rio Grande do Norte - UERN, Pau dos Ferros, Rio Grande do Norte, Brasil, livia.soares@ifma.edu.br
} 


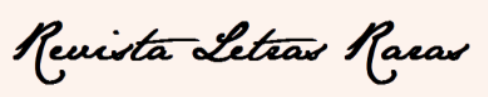

ISSN: 2317-2347 - v. 7, Edição Especial (2018).

As obras literárias de John Ronald Reuel Tolkien (J. R. R. Tolkien), tornaram-se objetos de fascinação entre leigos, cineastas e acadêmicos. Narrativas como O Hobbit (1937) e O Senhor dos Anéis (1954-1955) apresentam um universo maravilhoso com criaturas oriundas do folclore nórdico que influenciaram muitas gerações de leitores e, mesmo, de escritores. O Silmarillion (1999), Os Filhos de Húrin (2007), Béren e Lúthien (2017) e, mais recentemente, A Queda de Gondolin (2018), obras lançadas postumamente, são outras narrativas escritas pelo autor, nascido na África do Sul, que também exploram o imaginário mitológico da Terra-média.

$\mathrm{Na}$ narrativa de $O$ Hobbit, foco deste trabalho, encontramos uma comitiva formada por 14 membros que buscam recuperar o antigo lar dos anões, Erebor, ou, a Montanha Solitária, que foi tomada por um dragão nos tempos de glória do reino dos anões. Bilbo Bolseiro é o hobbit escolhido como $14^{\circ}$ membro do grupo e será o protagonista da história. Durante toda a narrativa, a comitiva passará por diversas aventuras nas quais enfrentará perigos na forma de trolls, lobos gigantes, gobblins (orcs), aranhas, além do próprio dragão no final da narrativa. O leitor acompanha a jornada de Bilbo, observando se o protagonista muda em algum aspecto sua maneira de ser e viver no mundo.

Partimos do pressuposto de que a jornada heroica, empreendida pelo protagonista, se apresenta como catalisadora de uma mudança profunda na forma como Bilbo, o protagonista da história, se percebe e percebe o mundo que o cerca. Em outras palavras, a aventura ajuda o indivíduo a desenvolver-se e tornar-se consciente de sua identidade como um ser indivisível e único no mundo, como atesta Jung (2008). Baseado nesse ponto de vista, esperamos, ao final da narrativa, escrita por Tolkien, verificar se a personalidade do hobbit sofreu alguma mudança significativa.

As narrativas de Tolkien são exemplos de trabalhos modernos que exploram a temática do herói, apresentando jornadas grandiosas dentro de um universo maravilhoso, geograficamente baseado no norte da Europa (López, 2004), que fazem o leitor imergir profundamente na história. São narrativas infanto-juvenis, com forte teor mitológico, desenvolvidas para serem contos de fadas (DURIÉZ, 2006). Em vista disso, é importante discutirmos sobre o mito do herói nas obras de Tolkien, assim como mapeá-lo, para que possamos entender mais detalhadamente a caminhada dos protagonistas, atribuindo-lhes novas significações. 


\section{Pevista Leteas Racas}

ISSN: 2317-2347 - v. 7, Edição Especial (2018).

No que diz respeito à jornada do herói, essa será aqui retratada a partir das fases de desenvolvimento propostas pelo antropólogo americano Joseph Campbell no seu livro O herói de mil faces (2007a), no qual ele aponta que o herói passa por diferentes estágios até alcançar seu objetivo. A jornada heroica é o meio que utilizaremos para compreendermos o processo de amadurecimento interior, na trajetória de Bilbo Bolseiro pela Terra-média.

Investigaremos, pois, nesta pesquisa, a narrativa $O$ Hobbit, de J. R. R. Tolkien. Nosso foco recairá na investigação da jornada do herói, realizada pela personagem Bilbo Bolseiro. Para a análise, será utilizada a edição de $2002^{\mathrm{a}}$ em português da obra citada, e nos valeremos dos estudos de Campell (2007a) acerca do mito do herói, que se encontra presente no livro $O$ herói de mil faces, para a compreensão da aventura heroica. Utilizaremos também o Dicionário dos Símbolos de Chevalier e Gheerbrant (2009), para nos auxiliar no entendimento dos símbolos que surgem durante a aventura.

\section{Os contos de fadas na perspectiva de Tolkien}

Tolkien nasceu em 1892, na África do Sul, e faleceu em 1973. Ele foi professor de Literatura Inglesa, na Universidade de Oxford, Inglaterra, e foi um emérito filólogo, conhecido mundialmente, que ajudou a compilar o Dicionário Avançado de Inglês de Oxford. Escreveu também os aclamados $O$ Silmarillion (1999), O Hobbit (1937) e $O$ Senhor dos Anéis (1954-1955), para citar alguns, além de contos e poemas, ainda pouco conhecidos no Brasil.

Quando criança, Tolkien observava paisagens e topografias de lugares que conhecia. Imagina-se que este hábito o tenha auxiliado na criação das paisagens do seu mundo imaginário. Outra paixão desenvolvida por Tolkien durante sua infância foi o interesse pela diversidade de idiomas, estimulado por sua mãe, especialmente o germânico, o galês e o finlandês, que formaram a base para o desenvolvimento das línguas da Terra-média. Paralelo a isto, cultivou um gosto aficionado por lendas e histórias que envolviam mitologia, especialmente aqueles contos de origem nórdica, por exemplo, conforme relata Duriez (2006). 


\section{Revista Leteas Racar}

ISSN: 2317-2347 - v. 7, Edição Especial (2018).

O escritor procurou testar na prática sua ideia de que, a literatura imaginativa pode integrar histórias e línguas, teoria e prática, realidade e ficção, permitindo acesso à dimensões da realidade que estão fora do alcance da ciência. Como relata Greggersen:

Sua hipótese [...] era que as verdades expressas pela linguagem mitológica têm a mesma racionalidade que aquelas expressas pela linguagem científica. E isso, com a vantagem de apelar para a razão, a imaginação e as emoções, campos dificilmente alcançáveis pela linguagem formal, mas nem por isso menos reais ou importantes. Para Tolkien, o mito permite vislumbrar dimensões da realidade ignoradas pela ciência, numa perspectiva holística e não fragmentária, aberta para a totalidade. Daí que ele o tenha escolhido como modelo para seu tipo de literatura. (GREGGERSEN, 2003, p. 22).

Tolkien utilizou-se da narrativa mítica para escrever suas histórias e as chamou de legendário, ou seja, um conjunto de lendas. Na visão dele, o passado da Inglaterra carecia de um conjunto de histórias míticas que relatassem façanhas heroicas, a semelhança dos contos nórdicos, como Beowulf, por exemplo, pelo qual era fascinado. Suas histórias são compostas por elfos, dragões, aranhas gigantes, orcs, hobbits, magos, anões, deuses e inúmeros heróis que protagonizam as narrativas. Os mapas disponibilizados nos livros, especialmente em $O$ senhor dos Anéis, nada mais são que desenhos do norte da Europa em um período pré-cristão ambientados em uma atmosfera medieval, como aponta Duriez (2006).

O legendário de Tolkien era, por ele considerado, uma composição de narrativas de contos de fadas. Tolkien relata, em seu ensaio Sobre contos de fadas (2013), que no Dicionário de Oxford, na entrada fairy-tale, podemos encontrar algumas definições pertinentes, registradas desde o ano de 1750. Tem-se, desse modo, as seguintes acepções: (a) um conto sobre fadas ou, de modo geral, uma lenda de fadas, com desdobramentos de sentido, (b) uma história irreal ou incrível, e (c) uma falsidade. Tolkien considerou as definições anteriores muito limitadas, pois elas não contemplavam a verdadeira essência da narrativa de fadas como ele as percebia. Em outras palavras, os chamados contos de fada pouco relatavam a presença de fadas, caso tomássemos ao pé da letra. Acerca disso, Tolkien discorre: 


\section{Reuista Leteas Racar}

ISSN: 2317-2347 - v. 7, Edição Especial (2018).

Disse que o sentido de "histórias sobre fadas" era demasiado restrito. É restrito demais mesmo que rejeitemos o tamanho diminuto, pois no uso normal em língua inglesa os contos de fadas não são histórias sobre fadas e elfos, mas histórias sobre o Reino Encantado, Faerie, o reino ou estado no qual as fadas existem. O Reino Encantado contém muitas coisas além dos elfos e das fadas, e além de anões, bruxas, trolls, gigantes ou dragões; contém os oceanos, o sol, a lua, o firmamento e a terra, e todas as coisas que há nela: árvore e pássaro, água e pedra, vinho e pão, e nós mesmo, seres humanos mortais, quando estamos encantados. (TOLKIEN, 2013, p. 10).

O autor elaborou, então, sua própria definição acerca do que seria um conto de fadas, mesmo sendo, como mesmo admitiu no seu ensaio, apenas uma pessoa curiosa discutindo sobre o assunto. De acordo com o exposto na citação acima, para Tolkien, contos de fadas são narrativas com aventuras que acontecem no Reino Encantado, em que heróis e elementos mitológicos (elfos, dragões, anões e magos, por exemplo) relacionam-se na produção de uma história maravilhosa. Conforme Tolkien (2013, p. 10), “[...] um 'conto de fadas' é aquele que toca ou usa o Reino Encantado, qualquer que seja seu propósito principal, sátira, aventura, moralidade, fantasia”.

Nas obras de Tolkien, o leitor é transportado ao âmago do gênero maravilhoso, em que se produzem acontecimentos que não podem ser explicados pelas leis do mundo real observável. É um mundo povoado por magos, dragões, elfos, anões cujas existências, segundo as leis daquele mundo, são vistas com "normalidade" ou passíveis de acontecerem sem a personagem ou o leitor questionar. Segundo Chiampi (1980), o conto maravilhoso não causa espanto porque a narrativa não estabelece nenhuma conexão com o mundo empírico.

Ainda segundo Chiampi (1980), na literatura maravilhosa, os personagens ou leitor da narrativa aceitam a existência de fenômenos meta-empíricos, pois eles constituem parte essencial daquele universo, diferentemente da literatura fantástica, conforme relata Todorov (2014), em que a personagem ou leitor hesita frente à estranheza dos eventos "sobrenaturais" que se desenrolam na história, uma vez que esse tipo de fenômeno não faz parte das leis do mundo imediato. Nessa perspectiva, a literatura maravilhosa e fantástica, embora tratem de eventos meta-empíricos, diferem quanto ao modo de abordagem dos fenômenos sobrenaturais.

Dentro do universo de fantasia de Tolkien, insere-se o subgênero mito, visto que, o autor desenvolve uma narrativa que conta o passado de um mundo e/ou de um povo. 


\section{Pevista Leteas Racas}

ISSN: 2317-2347 - v. 7, Edição Especial (2018).

Os mitos estão intimamente ligados aos fenômenos inaugurais como a criação dos mundos, da fauna, da flora e do homem. Ele está relacionado, conceitualmente, à própria literatura maravilhosa em si, já que os personagens, ou o leitor, não estranham os acontecimentos que se desenrolam em seu corpo narrativo. Nesta perspectiva, o romance tolkieniano busca esclarecer como a realidade foi criada e como surgiram os ancestrais das personagens da história. ${ }^{1}$

Neste subgênero literário, há a atuação de forças malignas que precisam ser combatidas e destruídas ou controladas pelos heróis. O embate da força do bem e das forças do mal geram batalhas que adquirem um tom grandiloquente a medida que a atrama se desenvolve. É precisamente nesse universo mítico e maravilhoso que as obras de Tolkien se inserem, retratando heróis e aventuras, perigos e façanhas grandiosas.

Os contos de fadas de Tolkien retratam as experiências de personagens que realizam a jornada heroica e atravessam situações que requerem mudanças interiores. $\mathrm{E}$ Bilbo Bolseiro é um bom exemplo disso. Contudo, para desempenhar essas façanhas, os indivíduos envolvidos precisam amadurecer em força e sabedoria, e isto acontece dentro das fases da jornada heroica proposta por Campbell (2007a), em que o herói enfrenta desafios, muitos deles perigosos, que o ajudam a desenvolver-se.

Tolkien desenvolveu seu legendário utilizando-se de narrativas com forte teor mitológico, dentro das quais há um consistente trabalho com arquétipos do inconsciente coletivo, largamente estudados por Jung (2000) e Von-Franz (2008). O arquétipo do herói, por exemplo, desperta na psique do protagonista pelo motivo da jornada heroica colocada em curso. Ao entrar em contato com essas imagens primordiais, a personagem “[...] passa a ampliar sua relação com o mundo e consegue se ver livre da perspectiva mesquinha e egoísta de desejos, de medos e de perspectivas ilusórias, fugazes e pontuais.” (LÓPEZ, 2004, p. 27).

\section{A jornada heroica de Campbell}

O mito tem grande presença e forte influência nas sociedades tribais e antigas, como Egito, Grécia, Roma, Mesopotâmia, etc. nas quais desempenha a função maior de

\footnotetext{
${ }^{1}$ As narrativas que contam a história do surgimento da Terra-média estão presentes em $O$ Silmarillion, de Tolkien, lançado em 1999. No Brasil, a obra foi lançada pela editora Martins Fontes e traduzida por Waldéa Barcelos.
} 


\section{Reuista Letear Racar}

ISSN: 2317-2347 - v. 7, Edição Especial (2018).

explicar a existência do ser humano e as relações dele com o mundo natural, conforme Campbell (2007a). Em todas as épocas e em todos os lugares, o homem tem produzido narrativas maravilhosas que o possibilitam se relacionar com o mundo material e imaterial. Conforme o autor, "as religiões, filosofias, artes, formas sociais do homem primitivo e histórico, descobertas fundamentais da ciência e da tecnologia e os próprios sonhos que nos provocam o sono surgem do círculo básico e mágico do mito." (CAMPBELL, 2007a, p. 15).

Campbell (2007a, p. 16), inquieto com a necessidade do homem de produzir essas fantasias, questiona: "Qual o segredo dessa visão intemporal? De que camada profunda vem ela? Por que é a mitologia, em todos os lugares, a mesma, sob variedades dos costumes? E o que ensina essa visão?”. Esses questionamentos nos conduzem à busca do motivo do surgimento de narrativas tão semelhantes entre si, em culturas que nunca estiveram em contato. É precisamente nesse curioso fenômeno que se insere o monomito de Campbell.

O monomito é uma estrutura narrativa que assume roupagens diferentes, segundo a cultura de cada povo. Campbell estudou inúmeros mitos, contos e histórias populares a fim de entender como essas histórias estavam organizadas e, se havia algo em comum entre elas. De acordo com o estudioso, todas as histórias e contos populares seguem uma mesma estrutura com as mesmas fases de desenvolvimento: Partida, Iniciação e Retorno. Essas fases são marcadas pela figura do herói, presente em todas as narrativas criadas pelo homem.

O herói do monomito, conforme Campbell (2007a), possui características excepcionais ou dons incomuns que o destacam de outras pessoas. Pode ser uma apatia pelas atividades da comunidade em que mora. Pode ser uma atitude crítica diante de alguns comportamentos de pessoas da comunidade. Pode ser ainda um deslumbramento ou vontade de saber o que há além dos limites do povoado. É possível perceber essa característica notadamente nos contos de fadas, em que sempre há a saída de algum personagem para conhecer o mundo.

Propp (1984), no seu livro Morfologia do conto maravilhoso, a semelhança de Campbell, propôs um esquema de construção dos contos russos que pode ser também aplicado às narrativas mitológicas. No esquema do autor, existem trinta e um momentos que podem ser identificados nas narrativas produzidas pelo homem. Nem todos os 


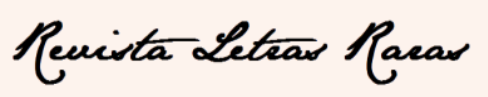

ISSN: 2317-2347 - v. 7, Edição Especial (2018).

pontos, contudo, estarão necessariamente presentes em todas as histórias. Alguns podem estar omissos ou levemente subentendidos.

Conforme citado, a aventura heroica é dividida em três grandes fases: Partida, Iniciação e Retorno. Cada área é subdividida em momentos que o herói perpassa até finalizar o ciclo da jornada. A fase da Partida compreende os seguintes momentos: $o$ chamado da aventura; o recusa do chamado; o auxílio sobrenatural; a passagem pelo primeiro limiar e o ventre da baleia. A fase da Iniciação é dividida em: o caminho de provas; o encontro com a deusa; a mulher como tentação; a sintonia com o pai; a apoteose e a benção última. E os momentos da fase do Retorno são: a recusa do retorno; a fuga mágica; a resgate com auxílio externo; a passagem pelo limiar do retorno; senhor dos dois mundos e liberdade para viver.

A jornada inicia com $O$ chamado da aventura, em que o herói é convidado a afastar-se do conforto do lar para empreender uma viagem para além dos limites conhecidos. É o primeiro passo dado na direção do desconhecido, em que crenças pessoais arraigadas são questionadas. Após o herói ser convocado para a aventura, segue $A$ recusa do chamado. Esse pode não querer aventurar-se por lugares estranhos, uma vez que a aventura o colocaria em contato com o desconhecido e consigo mesmo. Conforme Campbell (2007a, p. 67), “a recusa à convocação converte a aventura em sua contraparte negativa. Aprisionado pelo tédio [...] o sujeito perde o poder da ação afirmativa dotada de significado e se transforma numa vítima a ser salva”.

O auxílio sobrenatural vem em seguida. Caso o herói tenha decidido aceitar a aventura, este irá se encontrar com uma figura protetora, uma pessoa que o ajudará na tarefa de seguir em frente. Um velho ou velha o fornecerá amuletos mágicos que o protegerão das forças titânicas com que ele está prestes a entrar em contato.

A passagem pelo primeiro limiar é a próxima etapa da aventura. O herói encontra-se no limiar entre dois mundos: aquele que é conhecido e seguro, de onde este provém, e o novo mundo, perigoso e inexplorado, para onde está se dirigindo. "A pessoa comum está mais do que contente, tem até orgulho, em permanecer no interior dos limites indicados [...]." (CAMPBELL, 2007a, p. 82). A etapa $O$ ventre da baleia carrega a ideia do renascimento para o aventureiro. O herói atravessa uma morte simbólica ou uma auto aniquilação. O protagonista precisa deixar para traz crenças antigas para conhecer novos conceitos que a jornada o apresentará. 


\section{Revista Leteas Racar}

ISSN: 2317-2347 - v. 7, Edição Especial (2018).

A Iniciação é a segunda fase da jornada heroica. Após atravessar o Primeiro limiar e sofrer uma morte simbólica no Ventre da baleia, o herói passa pelo Caminho de provas, em que deverá sobreviver a uma sucessão de obstáculos. As provas que ele enfrentará representam as crises de percepção que precisavam acontecer para que sua consciência seja desenvolvida. Após vencer todas as provas colocadas no seu caminho, o herói realiza o casamento simbólico com a Deusa do Mundo. Esse é o teste final que o herói perpassa para obter a benção do amor que é a própria vida. Essa etapa conduz para o momento posterior, A mulher como tentação, em que a forma feminina, como símbolo da própria vida, aparece para o herói.

O indivíduo, logo após, confronta-se com o aspecto negativo do pai, na etapa $A$ sintonia com o pai. Este é o reflexo do próprio ego do herói oriundo da lembrança de proteção da mãe. O herói deve buscar esperança na figura masculina, por meio da qual, ele é protegido ao longo das experiências de iniciação. Consiste no abandono do monstro autogerado pelo complexo de édipo, restabelecendo, assim, uma relação saudável com a figura masculina.

A apoteose segue à etapa anterior. Nela, o protagonista se torna livre de todo temor e amarras conscientes e inconscientes. A concepção da apoteose, conforme Campbell (2007a, p. 146), reside no fato de a mente ser conduzida "[...] para além da experiência objetiva, para um domínio simbólico que deixa para trás a dualidade”. A dualidade, aqui, refere-se às concepções de deuses macho e fêmea, figuras simbólicas presentes em etapas anteriores. O último estágio da Iniciação é $A$ benção última. Aqui, o herói é encarado como um homem superior e busca, por intermédio do intercurso com os deuses, a graça deles, ou poder de sua substância sustentadora, que é tomada como o imperecível, além do tempo e espaço.

A última fase da aventura heroica é o Retorno. O protagonista, na maioria das histórias, retorna para o local de onde veio, levando consigo um artefato transmutador da vida que beneficiará a comunidade ou a si próprio. A primeira etapa dessa fase é $A$ recusa do retorno, em que o herói pode escolher não retornar para o seu lar, decidindo fixar residência em um outro local, ou mesmo escolhe viver realizando aventuras pelo mundo. O momento seguinte configura o que se chama de A fuga mágica. A fuga acontece por conta de o herói ter obtido o troféu com a oposição do guardião, ou, ainda, de ele retornar para a comunidade contrariando os deuses (poderes da vida) ou 


\section{Revista Leteas Racar}

ISSN: 2317-2347 - v. 7, Edição Especial (2018).

demônios. Isso acontecendo, o herói pode ser auxiliado para retornar para o mundo exterior, em $O$ resgate com auxílio externo. O mundo vai de encontro a ele com o propósito de levá-lo de volta para o seio da comunidade.

A passagem pelo limiar do retorno representa uma divisão entre retornar para o mundo cotidiano e a permanência no outro mundo, que antes era considerado desconhecido mas que agora o herói domina. Ele terá que aceitar as alegrias e tristezas passageiras do cotidiano e as banalidades da vida. A penúltima etapa refere-se à liberdade que o herói possui de ir e vir entre os dois mundos - conhecido e desconhecido -, denominada de $O$ senhor dos dois mundos.

Liberdade para viver é a etapa que finaliza a jornada. Após o indivíduo sair do conforto do lar, enfrentar provas e desafios, vencê-los e retornar para a comunidade de onde proveio, ele agora se depara com a liberdade para viver sua viva de um modo diferente comparado a antes. O herói está mudado, pois a forma como se auto percebe e percebe o mundo ao seu redor foi alterada.

É importante salientar que, nem todas as etapas presentes na jornada formulada por Campbell (2007a) aparecem obrigatoriamente em todos os contos. Pode acontecer de, em muitas narrativas, algumas das etapas mencionadas acima não existirem, como a sintonia com o pai, ou a união com a deusa, por exemplo.

\section{A jornada heroica de Bilbo Bolseiro}

A história apresentada no livro $O$ Hobbit, de J. R. R. Tolkien, narra a aventura um hobbit pela Terra-média, juntamente com um grupo de anões e um mago. Essa companhia enfrenta perigos na forma de trolls, orcs, lobos selvagens e aranhas para chegar, finalmente, a uma montanha, dentro da qual um dragão, chamado Smaug, guarda um tesouro roubado. Bilbo é o nome do hobbit que ingressa nessa aventura. E o tesouro roubado é dos anões.

Bilbo é um hobbit. E um hobbit, segundo Tolkien (2002b), é uma criatura pequena, rápida e com pés peludos. Eles são muitos ligados à natureza e à tranquilidade, preferindo a calma de seu lar/comunidade a participar de aventuras estranhas. Bilbo é filho de Beladona Tuk e Bungo Bolseiro e não se esperava que ele possuísse nenhuma característica do lado da sua mãe, pois ele muito parecia uma segunda cópia de seu pai, 


\section{Reuista Leteas Racas}

ISSN: 2317-2347 - v. 7, Edição Especial (2018).

tranquilo e não aventureiro. Mas Bilbo possuía um lado Tuk, ligado ao seu avô, que gostava de aventuras. Essa característica esperou o momento certo para emergir na vida do hobbit. "A oportunidade não apareceu até que Bilbo estivesse adulto, com mais ou menos cinquenta anos, vivendo na bonita toca de hobbit construída por seu pai, e que eu acabei de descrever para vocês.” (TOLKIEN, 2002a, p. 3).

A aventura de Bilbo Bolseiro será contada e analisada a seguir, tomando como base a jornada do herói de Campbell (2007a), anteriormente apresentada. Para a análise dos símbolos que aparecem durante a narrativa, utilizaremos o Dicionário dos Símbolos, de Chevalier e Gheerbrant (2009).

\subsection{A Partida}

A jornada de Bilbo pela Terra-média se inicia quando Gandalf, um mago, o aborda o hobbit no Condado, e diz estar à procura de alguém para participar de uma aventura, como consta no capítulo inicial, intitulado Uma festa inesperada: “- Muito bonito! - disse Gandalf. - Mas eu não tenho tempo para soprar anéis de fumaça esta manhã. Estou procurando alguém para participar de uma aventura que estou organizando, e está muito difícil achar alguém.” (TOLKIEN, 2002a, p. 4-5).

Bilbo, claramente, vê-se nervoso, uma vez que, participar de aventuras não fazia parte do estilo de vida dos hobbits, muito embora houvesse, na família, um parente, seu avô, chamado Urratouro Tuk, que gostava de aventuras. O chamado da aventura configura um ritual, como aponta Campbell (2007a), em que o limite familiar da vida é ultrapassado e antigas ideias e padrões emocionais não são mais adequados na relação do indivíduo com a realidade.

Na mesma conversa com Gandalf, Bilbo realiza a Recusa do chamado. Ele diz que aventuras o fazem se atrasar para o jantar e pede para o mago procurar aventureiros além da Colina ou do outro lado do Água, um rio da região. Essa recusa evidencia o choque que desequilibra a personalidade no processo de amadurecimento interior. Eis o que Bilbo diz, “- Sinto muito! Mas não quero aventuras, muito obrigado. Hoje não. Bom dia! Mas, por favor, venha tomar chá, a qualquer hora que quiser! Por que não amanhã? Venha amanhã! Até logo!”. (TOLKIEN, 2002a, p. 6). 


\section{Reuista Leteas Racas}

ISSN: 2317-2347 - v. 7, Edição Especial (2018).

No dia seguinte, o hobbit inicia a jornada na companhia de Gandalf, pois $A$ recusa do chamado é apenas momentânea. Nesse ponto, temos o que Campbell chama de $O$ auxílio sobrenatural. Gandalf é o guia e protetor do hobbit, uma vez que ficou responsável por procurar uma pessoa para compor a comitiva da aventura. Gandalf o escolheu como décimo quarto integrante da companhia porque, segundo ele, os guerreiros estavam ocupados lutando uns contra os outros em terras distantes e porque os heróis, naquela época, eram raros. (TOLKIEN, 2002a, p. 20-21).

Bilbo segue com Gandalf para o local, marcado com os anões, de se encontrarem. Essa etapa desenrola-se no capítulo seguinte, intitulado Carneiro assado. Nela, o hobbit realiza A primeira travessia do limiar, em que ultrapassa os limites conhecidos da região onde mora. "Além desses limites, estão as trevas, o desconhecido e o perigo, da mesma forma como, além do olhar paternal, há perigo para a criança e, além da proteção da sociedade, perigo para o membro da tribo." (CAMPBELL, 2007a, p. 82).

Nas Terras Solitárias, o protagonista depara-se com sua primeira aventura. Ele encontra três trolls, em meio às árvores, comendo carneiro assado. $\mathrm{O}$ grupo de anões é capturado e Gandalf os salva. Segundo Chevalier e Gheerbrant (2009), em O Dicionário dos Símbolos, trolls são representações claras dos instintos e conteúdos reprimidos que compõem a Sombra. Já a fogueira utilizada para assar os carneiros relaciona-se aos ritos iniciáticos. Na história, ela comunica a ideia de que Bilbo está passando por um processo de iniciação.

Após desvencilharem-se dos trolls, Bilbo chega à Valfenda e encontra os elfos da última casa amiga, como também é chamado o lugar. A habitação situa-se em um vale cortado por um rio e o chefe dos elfos chama-se Elrond. Este recorte cênico na narrativa refere-se à etapa Ventre da baleia, na divisão feita por Campbell, compondo a última etapa da primeira fase (Partida). Valfenda representa o ventre da baleia, em que Bilbo imerge para renascer, reforçando o motivo da passagem pelo limiar.

\subsection{A Iniciação}

A aventura de Bilbo prossegue e ele adentra o segundo estágio da jornada heroica, conforme Campbell (2007a), denominada de Iniciação. O Caminho de Provas é 


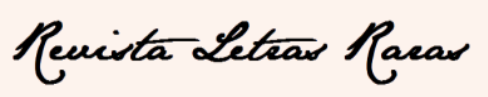

ISSN: 2317-2347 - v. 7, Edição Especial (2018).

a etapa mais aguardada desse estágio, pois compreende a existência de variadas provas pelas quais o herói terá que passar.

Após descansar e alimentar-se na casa dos elfos, Bilbo e companhia direcionamse para as Montanhas Sombrias, no capítulo Montanha acima, Montanha adentro. Nas Montanhas, é a primeira vez que o hobbit entra em contato com os orcs. O hobbit é capturado, juntamente com os anões, e levado à presença do grão-orc. Este é morto por Gandalf e todos fogem. Entretanto, Bilbo fica para trás, nos túneis, inconsciente e, quando acorda encontra o Um Anel de Sauron, o anel de poder, artefato em torno do qual a saga $O$ senhor dos Anéis se desenvolve. Encontra também Gollum, uma criatura viscosa, com olhos grandes, que habita uma caverna na raiz da montanha. $\mathrm{O}$ anel pertencia à Gollum, que o havia perdido nos túneis.

Bilbo consegue fugir da montanha e encontra a companhia de Thorin do lado de fora, na floresta. Ele já havia experimentado o poder de invisibilidade do anel e foi assim que conseguiu escapar dos túneis. Do lado de fora, o grupo é cercado por Wargs, grandes lobos selvagens que querem devorá-los. Os lobos podem simbolizar tendências regressivas no inconsciente do hobbit que necessitam ser aceitas. De acordo com Chevalier e Gheerbrant (2009), eles podem também representar a luz, o sol ou o herói guerreiro em desenvolvimento.

A companhia é salva pelas grandes águias das montanhas e todos são levados para as terras de Beorn, no capítulo Estranhos Alojamentos. Beorn é um troca-peles: ora um homem grande, ora um urso maior ainda. Ele é imprevisível, nem amigo e nem inimigo. Segundo o Chevalier e Gheerbrant (2009), “[...] o urso faz parte dos símbolos do inconsciente ctônico: lunar e, portanto, noturno, ele está ligado às paisagens internas da terra-mãe." (CHEVALIER; GHEERBRANT, 2009, p. 925). Na casa de Beorn, eles comem, descansam e obtém ajuda para continuarem.

Bilbo e a comitiva seguem, então, para a Floresta das Trevas. Essa resguarda um mistério ambivalente, conforme é salientado no Chevalier e Gheerbrant (2009), pois gera, ao mesmo tempo, angústia e serenidade, opressão e simpatia. No coração da floresta, o perigo espreita na forma de aranhas gigantes. O herói, enquanto descansa, é atacado por uma dessas criaturas e a enfrenta, matando-a. Após matá-la, ele se sente uma nova pessoa, mais corajosa. Bilbo passa por uma iniciação profunda, como atesta o simbolismo da aranha apontado por Chevalier e Gheerbrant (2009). A coragem de Bilbo 


\section{Revista Leteas Racar}

ISSN: 2317-2347 - v. 7, Edição Especial (2018).

está sendo desenvolvida aos poucos, o que possibilita o surgimento do arquétipo do herói na psique de Bilbo.

Durante a travessia da floresta, os anões são capturados pelas aranhas. E Bilbo, utilizando o anel mágico, os salva daqueles animais que queriam devorá-los. Logo em seguida, os mesmos anões são capturados pelos elfos da floresta e levados para seus domínios, liderados por Thranduil. O hobbit liberta os anões de suas celas, no capítulo Barris Soltos, colocando-os em barris que seriam conduzidos para a Cidade do Lago, Esgaroth, onde homens residem.

Em Esgaroth, a comitiva é bem recebida. O rei da cidade os acolhe e os alimenta, e eles puderam mais uma vez descansar. À Bilbo e companhia foram concedidos barcos e armas que os auxiliaram na ida para a Montanha Solitária. Na montanha, após Bilbo encontrar a porta de entrada, ele, finalmente, desempenha a função para o qual foi contratado: a de ser um ladrão. Desce por um longo corredor escuro para dentro da montanha. Bilbo estava apreensivo. Não sabia o que iria encontrar lá embaixo. Estava para enfrentar sua maior provação, o encontro com o dragão, e roubar a Pedra Arken, também chamada de "A Pedra do Rei”. No final do túnel, o herói depara-se com a seguinte cena: "Está quase escuro, de modo que sua vastidão [do interior da montanha] pode ser apenas vagamente imaginada; mas, no chão de pedra junto à porta, ergue-se um grande clarão. O clarão de Smaug." (TOLKIEN, 2002a, p. 209-210).

O dragão acordado no interior da montanha indica que as últimas tendências negativas, como ganância e violência, estavam despertas na mente do herói e que aquela era a oportunidade para encará-las e assimilá-las. Ao conversar com Smaug, ele reconhece a grandeza do dragão, relatando que ele é a "Maior e Mais Importante das Calamidades" (TOLKIEN, 2002a, p. 216). Este ato proporciona a Bilbo a aceitação de suas tendências negativas, e fica bem claro simbolicamente quando, após a conversa, Smaug sai da montanha e segue para a cidade do lago. Ou seja, ele vai embora. O fato de o dragão afastar-se da montanha e de Bilbo configura a assimilação dos aspectos negativos. O dragão não é mais uma ameaça.

No capítulo Fora de Casa, o hobbit adentra a etapa chamada A benção última, cuja principal característica é a conquista de uma benção, ou seja, algo valioso. Bilbo encontra a Pedra Arken. Esse é o momento de maior vislumbre do desenvolvimento da 


\section{Reuista Letear Racar}

ISSN: 2317-2347 - v. 7, Edição Especial (2018).

personalidade do protagonista na narrativa. Segundo Von Franz (2008, p. 278), “[...] o self é simbolizado, com muita frequência, na forma de uma pedra, preciosa ou de outro tipo qualquer”. O ato de pegar a pedra, a apropriação de algo sólido, que reluz com muitas cores, representa a apropriação de si mesmo em meio a tantos tesouros disponíveis. Em outras palavras, o herói amadureceu e encontra-se com o Self, representação do crescimento da psique para a totalidade. É a união dos opostos, verdadeiro sentido da jornada heroica.

\subsection{O Retorno}

Após A Batalha dos Cinco Exércitos, em que Bilbo se viu envolvido e que, anos depois, ele assumiu como sendo a melhor aventura que já havia participado, é o momento de o herói retornar para a comunidade de origem. A terceira fase da grande jornada, $O$ Retorno, inicia-se.

A recusa do chamado acontece quando o herói não deseja voltar para casa e decide ficar nas regiões desconhecidas e viver outras aventuras, sendo a benção alcançada, guardada somente para si. Entretanto, isso não acontece com Bilbo. Durante toda a aventura, o hobbit ansiava por retornar para casa, sonhando com sua comida, com sua sala confortável e o fogo da lareira. No decurso da aventura, entretanto, esse desejo foi se tornando menor. Mas, mesmo assim, ele ansiava retornar para seu lar.

O herói agora retorna para casa com a benção que lhe foi concedida - uma nova concepção de si e do mundo -, guiado mais uma vez por Gandalf, o mago. O retorno sugere que o herói levará consigo algo que beneficiará a comunidade em que vive. Ele tem a responsabilidade de retornar e dividir suas descobertas e experiências com o grupo.

A passagem pelo limiar do retorno acontece quando Gandalf e Bilbo chegam ao limite das terras conhecidas, no capítulo A última etapa. Nessa trajetória, o herói retorna aos limites das regiões conhecidas e habitadas. Na narrativa, é exatamente nesse limite que a comitiva de Thorin encontrou os trolls, um ano atrás, e Bilbo deparou-se com o primeiro perigo.

Tendo agora retornado para sua comunidade, o herói se torna o que Campbell denominou de $O$ senhor dos dois mundos. Ele possui o conhecimento do mundo 


\section{Reuista Letear Racar}

ISSN: 2317-2347 - v. 7, Edição Especial (2018).

conhecido, o Condado, e adquiriu a experiência do mundo desconhecido, o Ermo. Essa característica de ser o senhor dos dois mundos confere ao herói uma liberdade de mobilidade entre os dois espaços. De fato, Bilbo realizou outras viagens após a grande aventura para Erebor. Com frequência, o hobbit visitava os elfos em Valfenda ou ia mais além, no Ermo.

No final da aventura, o protagonista já não era mais o hobbit que saiu do Condado havia um tempo e Gandalf apontou isso em uma fala quando eles chegaram no limiar das terras conhecidas: “[...] - Meu querido Bilbo! - disse ele. - Há algo de errado com você! Não é mais o hobbit que era.” (TOLKIEN, 2002a, p. 290). O mago percebe o amadurecido do herói e a mudança na sua personalidade como algo positivo.

Bilbo agora estava livre, pois sua percepção da vida estava modificada. Não percebia mais o mundo somente como o Condado em si: com seus rios, florestas e pessoas conhecidas. O mundo era algo maior que ele e aquela região. A jornada o fez se autoconhecer, possibilitando o desenvolvimento de potenciais latentes. Muitas outras aventuras ele realizou depois, mas esta foi a que ele mais gostou e relatou nos anos subsequentes para aqueles que estavam dispostos a ouvir.

\section{Considerações Finais}

Neste trabalho, nos propomos a compreender a aventura heroica empreendida pela personagem Bilbo Bolseiro, na narrativa $O$ Hobbit, de J. R. R. Tolkien. Para tanto, nos valemos do estudo de Campbell (2007a) acerca da jornada heroica e analisamos a narrativa seguindo as divisões propostas pelo mitólogo americano: Partida, Iniciação e Retorno.

Como exposto, o monomito é uma estrutura narrativa que assume roupagens diferentes, segundo a cultura de cada povo. De acordo com Campbell (2007a), todas as histórias e contos populares seguem uma mesma estrutura com as mesmas fases de desenvolvimento. Essas fases são atravessadas por uma figura arquetípica chamada de herói, presente em todas as narrativas maravilhosas criadas pelo homem.

Na primeira parte da análise, também intitulada de $A$ Partida, o hobbit recebe de Gandalf a proposta da aventura. Apreensivo, ele a recusa, pois a ideia de sair do lar o amedrontava, uma vez que Bilbo estava fortemente ligado ao ambiente conhecido e 


\section{Reuista Leteas Paear}

ISSN: 2317-2347 - v. 7, Edição Especial (2018).

previsível. Na mente do protagonista, naquele momento, a personalidade passa por uma lesão psíquica e velhos conceitos e atitudes passam a ser questionados e modificados.

Após superar o estado de conforto e enfrentar os primeiros obstáculos, na forma de trolls, Bilbo adenta o segundo estágio de desenvolvimento proposto por Campbell $A$ Iniciação. Nessa fase, Bilbo passar por diversas provas e se depara com diversos obstáculos que o fazem mudar progressivamente conceitos pessoais e atitudes fixas acerca de si e da vida como um todo. A personalidade dele é posta em conflito variadas vezes, e por variadas vezes a experiência do hobbit é ampliada, o que reflete diretamente no desenvolvimento da coragem, por exemplo.

À guisa de conclusão, a aventura de Bilbo Bolseiro pela Terra-média o modifica demasiado em níveis muito profundos. Aspectos como coragem, resolução de conflitos em situações difíceis, companheirismo, amizade, justiça, etc. são desenvolvidos e/ou ampliados. O protagonista passou por diversas provas durante a jornada que acarretaram revisão de conceitos e atitudes. No final da narrativa, o herói apresenta-se modificado: o narrador aponta que Bilbo realizou outras aventuras pela Terra-média e visitou os elfos e as montanhas.

Apontamos, dessa forma, a necessidade de outras histórias de Tolkien também serem estudadas sob o viés dos estudos de Campbell, para que possamos compreender e ressignificar as narrativas e as personagens presentes nelas. Obras como $O$ Senhor dos Anéis (1954-1955), O Silmarillion (1999), Os Filhos de Húrin (2007), Berén e Lúthien (2017) e, mais recentemente, A Queda de Gondolin (2018) são exemplos de outras narrativas do escritor que também trabalham com jornadas heroicas e que podem ser analisadas à luz dos estudos de Campbell.

\section{REFERÊNCIAS}

CAMPBEL, J. O herói de mil faces. São Paulo: Pensamento, 2007a. O poder do mito. São Paulo: Palas Atena, 2007b.

CHEVALIER, J.; GHEERBRANT, A. Dicionário dos símbolos: mitos, sonhos, costumes, gestos, formas, figuras, cores, números. Tradução de Vera da Costa e Silva. 23.ed. Rio de Janeiro: José Olympio, 2009.

CHIAMPI, I. O Realismo Maravilhoso. São Paulo: Perspectiva, 2015. 


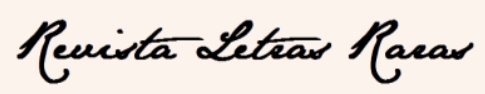

ISSN: 2317-2347 - v. 7, Edição Especial (2018).

DURIEZ, C. $O$ dom da amizade: Tolkien e C. S. Lewis. Tradução de Ronald Eduard Kyrmse. Rio de Janeiro: Nova Fronteira, 2006.

GREGGERSEN, G. O Senhor dos Anéis: da fantasia à ética. Viçosa: Ultimato, 2003.

JUNG, K. G. Os arquétipos e o inconsciente coletivo. Petrópolis: Vozes, 2000.

. Chegando ao inconsciente. In: JUNG, K. J. (Org). O homem e seus símbolos. Tradução de Maria Lúcia Pinho. Rio de Janeiro: Nova Fronteira, 2008, p. 15-132.

LOPEZ, R. S. O senhor dos anéis e Tolkien: o poder mágico da palavra. São Paulo: Devir: Arte e Ciência, 2004.

PROPP, V. I. Morfologia do conto maravilhoso. Rio de Janeiro: Forense Universitária, 2006.

TODOROV, T. Introdução à literatura fantástica. São Paulo: Perspectiva, 2014.

TOLKIEN, J. R. R. Árvore e folha. Tradução de Ronald Eduard Kyrmse. São Paulo: WMF Martins fontes, 2013.

O Hobbit. Tradução de Lenita Maria Rímoli Esteves e Almiro Pisetta. São Paulo: Martins Fontes, 2002a.

O Senhor dos Anéis: A sociedade do anel. Tradução de Lenita Maria Rímoli Esteves e Almiro Pisetta. São Paulo: Martins Fontes, 2002b.

O Senhor dos Anéis: As duas torres. Tradução de Lenita Maria Rímoli Esteves e Almiro Pisetta. São Paulo: Martins Fontes, 2002c.

O Senhor dos Anéis: O retorno do rei. Tradução de Lenita Maria Rímoli Esteves e Almiro Pisetta. São Paulo: Martins Fontes, 2002d.

Fontes, 2015.

O Simarillion. Tradução de Waldéa Barcellos. São Paulo WMF Martins

VON FRANZ, M. L. O processo de individuação. In: JUNG, K. G. (Org.). O homem e seus símbolos. Tradução de Maria Lúcia Pinho. Rio de Janeiro: Nova Fronteira, 2008, p. 207-308. 